\title{
Give One a Fish or Teach One to Fish: An Exploration on Intra-Entity Transfers
}

\author{
Daniel Hsiao \\ Texas A\&M University Commerce \\ Lei Han \\ Niagara University
}

Advanced accounting covers a series of challenging topics including business combination and financial statement consolidation. Students in advanced accounting class often have a hard time understanding the consolidation journal entries for intra-entity transfers. We develop an innovative "do-it-yourself" approach to teaching this difficult topic. To corroborate the effectiveness of this new approach relative to the traditional method, we randomize these two approaches in different sections and collect data from both samples, including grades on a quiz on intra-entity transfers and responses in an end-of-class survey. Both the quiz performance and survey feedback indicate that this new approach to teaching consolidation journal entries for intra-entity transfer is more effective than the traditional method demonstrated in current textbooks.

Keywords: intra-entity transfers, consolidation journal entry, advanced accounting

\section{INTRODUCTION}

Advanced accounting covers a series of challenging topics including business combination and financial statement consolidation (Christensen et al, 2019; Hamlen, 2019; Hoyle et al, 2015; Jeter and Chaney, 2019). Prior studies show that accounting students have a hard time understanding the consolidation journal entries (CJEs hereafter) for intra-entity transfers (Davis and Largay, 2006; Maksy, 2017; Masky and Zheng, 2008; Murphy and McCarthy, 2010). The academia has been encouraged to develop an effective approach to enhancing student learning on this complex subject (Armitage, 1991; Murphy and McCarthy, 2010).

The traditional approach, adopted by most textbooks, introduces the CJEs straight away without explaining in much detail why the entries are necessary. We developed a new approach to teaching this difficult topic by offering a standard format and pre-defined steps for students to derive the entries by themselves. This guided "do-it-yourself" approach creates a learning environment where students have to think over the intra-entity transfers from different angles, including the subsidiary's, the parent's and the consolidated entity's, gain a deeper understanding about the transactions and develop a solution mostly on their own.

More important, when comparing the new approach to the traditional approach, students strongly agree or agree that (1) the new approach allows them to gain a better understanding on why a certain account 
would be under- (or over-) estimated in lieu of CJEs adjustment, (2) the new approach is a more effective tool in studying the topic of intra-entity transfer of inventory than the traditional approach, and that (3) they recommend to use the new approach in teaching the topic in the future. Overall, the students' comments from the survey indicate that the new approach was well received and deemed as an effective method of covering the topic of intra-entity transfer of inventory.

\section{OVERVIEW}

The purpose of the study is to introduce the new approach to learning consolidation journal entries for intra-entity transfer of inventory and assesses the new approach based on students' performance in the quiz and feedback from the end-of-class survey.

\section{New Approach}

The new approach offers the format and pre-defined steps for students to derive the consolidation journal entries by themselves.

First, students are given twenty minutes to work on deriving the consolidation journal entries. The format given is as follows. Students are required to complete the analysis of the transaction in Year $\mathbf{1}$ and fill the first half of the table first, and then move on to the analysis for Year 2.

In Year 1, subsidiary sold 10 items of inventory (costing $\$ 8$ per item) to parent at $\$ 10$ each, and parent resold 6 such items at $\$ 12$ each to an outside customer.

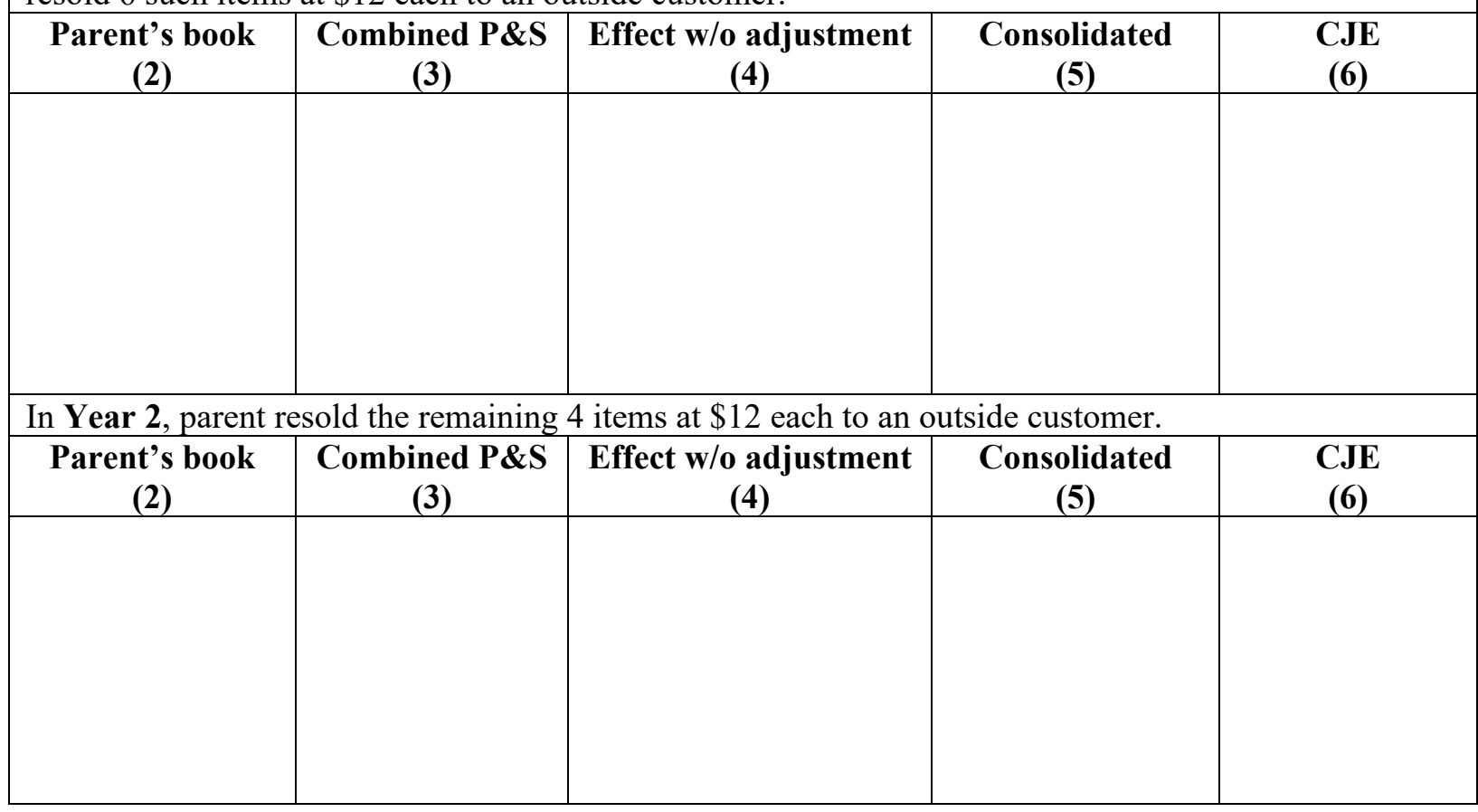

In each year, the following pre-defined four steps should be strictly followed:

- Step 1: Based on the transactions provided, prepare journal entries in Parent's book/column (1) and Subsidiary's books/column (2) respectively.

- Step 2: In column (3) Combined P\&S, combine the journal entries from Parent's book/column (1) and Subsidiary's books/column (2).

- Step 3: In column (5) Consolidated, prepare journal entries based on the same transaction assuming parent and subsidiary are essentially one entity. 
- Step 4: Compare the journal entry in column (3) Combined P\&S to the entry in column (5) Consolidated, identify the difference (overestimate or underestimate) by filling the column (4) Effect w/o adjustment.

- Step 5: In column (6) CJE (consolidation journal entry), create a journal entry (or entries) to offset the effect identified in column (4) Effect w/o adjustment.

Then, the instructor takes five minutes to go over the solution as follows:

\begin{tabular}{|c|c|c|c|c|c|c|}
\hline $\begin{array}{c}\text { Subsidiary's } \\
\text { book (1) }\end{array}$ & $\begin{array}{l}\text { Parent's } \\
\text { book (2) }\end{array}$ & $\begin{array}{r}\text { Combin } \\
\text { P\&S (3 } \\
\end{array}$ & & $\begin{array}{c}\text { Effect w/o } \\
\text { adjustment (4) }\end{array}$ & $\begin{array}{c}\text { Consolidated } \\
(5)\end{array}$ & CJE (6) \\
\hline $\begin{array}{l}\text { Dr. Cash } 100 \\
\text { Cr. Sales } 100 \\
\text { Dr. COGS } 80 \\
\text { Cr. Inventory } \\
80\end{array}$ & $\begin{array}{l}\text { Dr. Inventory } \\
100 \\
\text { Cr. Cash } \\
100 \\
\\
\text { Dr. Cash } \\
72 \\
\text { Cr. Sales } 72 \\
\text { Dr. COGS } 60 \\
\text { Cr. Inventory } \\
60\end{array}$ & $\begin{array}{l}\text { Dr. Cash } \\
\text { COGS } \\
\text { Cr. Sales } \\
\text { Inventory }\end{array}$ & $\begin{array}{r}72 \\
140 \\
172 \\
40\end{array}$ & $\begin{array}{l}\text { COGS over } 92 \\
\text { Sales over } 100 \\
\text { Inventory over } 8\end{array}$ & $\begin{array}{l}\text { Dr. Cash } 72 \\
\text { Cr. Sales } 72 \\
\text { Dr. COGS } 48 \\
\text { Cr. Inventory } \\
48\end{array}$ & $\begin{array}{l}\text { Dr. Sales } \\
100 \\
\text { Cr. COGS } \\
100 \\
\\
\text { (G) } \\
\text { Dr. COGS } \\
8 \\
\text { Cr. } \\
\text { Inventory } 8\end{array}$ \\
\hline $\begin{array}{c}\text { In Year 2, pare } \\
\text { Subsidiary's } \\
\text { book (1) }\end{array}$ & $\begin{array}{l}\text { esold the rema } \\
\text { Parent's } \\
\text { book (2) }\end{array}$ & $\begin{array}{r}\text { ng } 4 \text { items } \\
\text { Combin } \\
\text { P\&S (3 }\end{array}$ & $\frac{@ \$}{\text { ed }}$ & $\begin{array}{c}\text { each to an outside } \\
\text { Effect w/o } \\
\text { adjustment (4) }\end{array}$ & $\begin{array}{l}\text { stomer. } \\
\text { Consolidated } \\
\text { (5) }\end{array}$ & CJE (6) \\
\hline & $\begin{array}{l}\text { Dr. Cash } 48 \\
\text { Cr. Sales } \\
48 \\
\text { Dr. COGS } \\
40 \\
\text { Cr. Inventory } \\
40\end{array}$ & $\begin{array}{l}\text { Dr. Cash } \\
\text { COGS } \\
\text { Cr. Sales } \\
\text { Inventory }\end{array}$ & $\begin{array}{l}48 \\
40 \\
48 \\
40\end{array}$ & $\begin{array}{l}\text { COGS over } 8 \\
\text { Inventory under } 8 \\
\text { Accumulate } \\
\text { RE over } 8 \\
\text { COGS over } 8\end{array}$ & $\begin{array}{l}\text { Dr. Cash } 48 \\
\text { Cr. Sales } 48\end{array}$ & $\begin{array}{l}\text { Dr. RE } 8 \\
\text { Cr. COGS } \\
8\end{array}$ \\
\hline
\end{tabular}




\section{Traditional Approach}

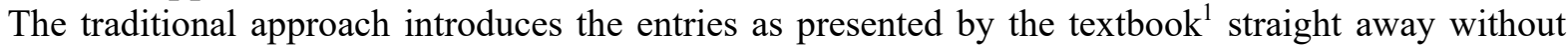
giving much detail about why the entries are necessary.

\section{SAMPLES AND EXPERIMENTAL DESIGN}

The experiment was administered in the advanced accounting class of a regional four-year private university over three fall semesters between 2016 and 2018. Two sections of students from the advanced accounting class participated in the assessment in each semester. The new and the traditional approaches were assigned to the two sections randomly. All six sections were taught by the same instructor. In total, 137 students' quiz grades and 142 survey responses were collected.

In each semester, as the instructor starts to cover intra-entity transactions, four class activities are administered in the following sequence for both sections.

\section{(1) Assigned approach}

Explain the intra-entity inventory sales/purchases based on the approach assigned. The class section that is randomly assigned the new approach will follow the format and pre-defined steps to derive the consolidation journal entries by themselves. The other section that is assigned the traditional approach will be given the consolidation journal entries right away and learn on how to apply them, without much detail on why the entries are needed.

(2) Quiz after the assigned approach

A quiz (see Appendix A) is administered to both classes right after the topic of intra-entity inventory sales/purchases has been introduced for the first time in the assigned approach. The quiz is then collected and graded. The two-sample t-test results based on the quiz grades from different samples (the section assigned to the new approach and the sections to the traditional approach) are displayed in Table 1. The average grade of the students who are taught in the new approach is $58.0 \%$, and the average grade of the peer group taught in the traditional approach is $52.7 \%$. The relatively low average grade in both sections is consistent with how difficult the covered topic is and the fact that the quiz is given right after the topic is covered. The difference in average grades between two sections is statistically significant at the 0.01 level, indicating that the students did significantly better in the quiz if the topic was introduced in the new approach than the traditional approach.

TABLE 1

\section{COMPARISON OF QUIZ GRADES BETWEEN TWO SECTIONS DURING 2016-2018}

\begin{tabular}{|l|c|c|c|}
\hline Assigned Approach to Start & No. of Obs. & Quiz Grade & T-stat (one-tail) \\
\hline Approach 1 (traditional) & 59 & $52.7 \%$ & 2.31 (p-value: 0.01) \\
\hline Approach 2 (new) & 78 & $58.0 \%$ & \\
\hline
\end{tabular}

\section{(3) Demonstrate the other approach}

The other approach is then illustrated. By the end of this activity, all students from both sections should have studied intra-entity transfer of inventory in both approaches, even though in different sequence. This activity is necessary to get students ready for developing their perspectives on the relative effectiveness of the two approaches in the end-of-class survey.

(4) End-of-class survey

At the end of the class, a survey (see Appendix B) with 7 questions is administered to students of both sections, to get their perspectives on the new approach relative to the traditional one. The first 3 questions ask students to indicate their level of agreement on the statements about the new approach itself and the next 3 ask about the new approach relative to the traditional one. The last question asks for students' comments. 
Based on the results from the survey (see Table 2), students reflect very positively about the new approach. $81 \%$ participants agreed or strongly agreed that the new approach provides a clear presentation on how individual companies (the parent and the subsidiary) booked the sales or purchased on their own books. 79\% participants agreed or strongly agreed that the new approach provides a clear presentation on how to derive the combined amounts (of sales, cost of goods sold, inventory, etc.), before the adjustments by CJEs. $74 \%$ participants agreed or strongly agreed that the new approach provides a clear presentation on how to derive the consolidated amounts (of sales, cost of goods sold, inventory, etc.), when parent and subsidiary were treated a consolidated entity.

\section{TABLE 2 \\ RESULTS FROM THE END-OF-CLASS SURVEY}

\begin{tabular}{|l|c|c|c|c|c|}
\hline Question & Strongly Agree & Agree & Neutral & Disagree & $\begin{array}{r}\text { Strongly } \\
\text { Disagree }\end{array}$ \\
\hline \multicolumn{2}{|l|}{ Please note: Approach 2 is the new approach with format and pre-defined steps, and Approach 1 is }
\end{tabular}
the traditional approach.

(1) Approach 2 provided a clear presentation on how individual companies (the parent and the subsidiary) booked the sales or purchases on their own books.

\begin{tabular}{|l|c|c|c|c|c|}
\hline Q1 & $28 \%$ & $53 \%$ & $15 \%$ & $4 \%$ & $1 \%$ \\
\hline
\end{tabular}

(2) Approach 2 provided a clear presentation on how to derive the combined amounts (of sales, cost of goods sold, inventory, etc.), before the adjustments by CJEs.

\begin{tabular}{|l|c|c|c|c|c|}
\hline Q2 & $22 \%$ & $57 \%$ & $19 \%$ & $2 \%$ & $0 \%$ \\
\hline
\end{tabular}

(3) Approach 2 provided a clear presentation on how to derive the consolidated amounts (of sales, cost of goods sold, inventory, etc.), when parent and subsidiary were treated a consolidated entity.

\begin{tabular}{|l|c|c|c|c|c|}
\hline Q3 & $14 \%$ & $60 \%$ & $20 \%$ & $4 \%$ & $1 \%$ \\
\hline
\end{tabular}

(4) Approach 2 allowed me to gain a better understanding on why a certain account would be under(or over-) estimated in lieu of CJE adjustment.

\begin{tabular}{|l|c|c|c|c|c|}
\hline Q4 & $17 \%$ & $51 \%$ & $25 \%$ & $7 \%$ & $1 \%$ \\
\hline
\end{tabular}

(5) Approach 2 is a more effective tool in studying the topic of intra-entity transfer of inventory than Approach 1.

\begin{tabular}{|l|c|c|c|c|c|}
\hline Q5 & $28 \%$ & $39 \%$ & $26 \%$ & $5 \%$ & $1 \%$ \\
\hline
\end{tabular}

(6) I recommend using Approach 2 in teaching this topic in the future.

\begin{tabular}{|l|c|c|c|c|c|}
\hline Q6 & $28 \%$ & $43 \%$ & $25 \%$ & $3 \%$ & $1 \%$ \\
\hline
\end{tabular}

When compared to the traditional approach, students believe the new approach has its merit. 68\% participants agreed or strongly agreed that the new approach allows them to gain a better understanding on why a certain account would be under- (or over-) estimated in lieu of consolidation journal entry adjustment. 
$68 \%$ participants agreed or strongly agreed that the new approach is a more effective tool in studying the topic of intra-entity transfer of inventory than the traditional approach. $71 \%$ participants recommend to use the new approach in teaching the topic in the future.

In the comment box provided by the last question, students are invited to leave comments as they see fit. All comments are included in Appendix C.

The new approach introduces in this study is limited in that it uses scenarios based on up-stream transfers. However, for an illustration of down-stream transfers, the scenarios can be easily modified, and the consolidation journal entries can be changed accordingly.

We recommend that the new approach should be presented when the study of CJEs for transfers just starts. Our teaching experience shows that usually, after the hands-on experience, students would understand the reason for eliminations by journals, because they would see easily how certain accounts could be over- or underestimated if the adjustments were not made. We suggest that instructors formally cover the entries after the practice to reinforce the concept.

\section{CONCLUSION}

To answer the call for an effective approach to teaching consolidation, we developed a new method of teaching consolidation journal entries for intra-entity transfers. Instead of handing the journals directly to students, we provided them a standard format and asked them to follow pre-defined steps to derive the journals all by themselves. To corroborate the effectiveness of the new approach, we implemented the new approach in advanced accounting sections for three semesters alongside with control sections using the traditional approach, and collected data including students' performance on topic-related quiz and their responses in an end-of-class survey. The findings indicate that the new approach is more effective than the traditional approach and is a promising solution to enhancing students' learning on the challenging topic.

\section{ENDNOTE}

1. Hoyle, J.B., T.F. Schaefer, and T.S. Doupnik. 2015. Advanced Accounting. 12th edition. New York, NY: McGraw-Hill/Irwin.

\section{REFERENCES}

Armigate, J. (1991). Academicians' and practitioners' views on the content and importance of the advanced financial accounting course. Journal of Accounting Education, 9(2), 327-339.

Christensen, T., Cottrell, D., \& Budd, C. (2019). Advanced Financial Accounting (12th edition). New York, NY: McGraw-Hill/Irwin.

Davis, M.L., \& Largay J.A. (2006). The consolidation dilemma-understanding The Issues. Journal of Theoretical Accounting Research, 2(1), 35-61.

Hamlen, S. (2019). Advanced Accounting (4th edition). Westmont, IL: Cambridge Business Publishers.

Hoyle, J.B., Schaefer, T.F., \& Doupnik. T.S. (2015). Advanced Accounting (12th edition). New York, NY: McGraw-Hill/Irwin.

Jeter, D.C., \& Chaney, P.K. (2019). Advanced Accounting (7th edition). Hoboken, NJ: Wiley.

Maksy, M. (2017). Factors associated with student performance in advanced accounting: An empirical study at a commuter university. Journal of Applied Business and Economics, 19(9), 42-59.

Maksy, M., \& Zheng, L. (2008). Factors associated with student performance in advanced accounting and auditing: An empirical study in a public university. Accounting Research Journal, 21(1), 16-32.

Murphy, E.A., \& McCarthy, M.A. (2010). Teaching consolidations accounting: An approach to easing the challenge. American Journal of Business Education, 3(11), 101-110. 


\section{APPENDIX A: QUIZ ON TRANSFER OF INVENTORY}

\section{Advanced Accounting Section:}

Name:

(1) During 2012, Von Co. sold inventory to its wholly-owned subsidiary, Lord Co. The inventory cost $\$ 30,000$ and was sold to Lord for $\$ 44,000$. From the perspective of the combination, when is the $\$ 14,000$ gain realized? (2 points)
A) When Lord pays Von for the goods.
B) When Von sold the goods to Lord.
C) When the goods are used by Lord.
D) When the goods are sold to a third party by Lord.
E) No gain can be recognized since the transaction was between related parties.

(2) If a subsidiary sold products to its parent company during the year but parent did NOT make any necessary consolidation entries to adjust the effect on the worksheet at the end of the year, then The consolidated sales revenue would be estimated; ( 2 points) The consolidated cost of goods sold would be estimated. (2 points)

(3) King Corp. owns $85 \%$ of James Co. King uses the equity method to account for this investment. During 2015, King sells inventory to James for $\$ 500,000$. The inventory originally cost King $\$ 420,000$. At $12 / 31 / 15,25 \%$ of the goods were still in James' inventory. (4 points)

Required: Prepare the Consolidation Entry TI and Consolidation Entry G for the consolidation worksheet.

\begin{tabular}{|c|l|l|l|}
\hline Transaction & Account & Debit & Credit \\
\hline (TI) & & & \\
\hline & & & \\
\hline & & & \\
\hline (G) & & & \\
\hline & & & \\
\hline & & & \\
\hline & & & \\
\hline
\end{tabular}

\section{APPENDIX B: END-OF-CLASS SURVEY}

(Approach 2 is the new approach with format and pre-defined steps, and Approach 1 is the traditional approach)

(Q1) Approach 2 provided a clear presentation on how individual companies (the parent and the subsidiary) booked the sales or purchases on their own books.

Strongly Agree ${ }^{C}$ Agree $^{\mathrm{C}}$ Neutral $^{\mathrm{C}}$ Disagree $^{\mathrm{C}}$ Strongly Disagree 
(Q2) Approach 2 provided a clear presentation on how to derive the combined amounts (of sales, cost of goods sold, inventory, etc.), before the adjustments by CJEs.

\section{Strongly Agree $^{\mathrm{C}}$ Agree $^{\mathrm{C}}$ Neutral $^{\mathrm{C}}$ Disagree ${ }^{\mathrm{C}}$ Strongly Disagree}

(Q3) Approach 2 provided a clear presentation on how to derive the consolidated amounts (of sales, cost of goods sold, inventory, etc.), when parent and subsidiary were treated a consolidated entity.

\section{Strongly Agree ${ }^{\mathrm{C}}$ Agree ${ }^{\mathrm{C}}$ Neutral ${ }^{\mathrm{C}}$ Disagree ${ }^{\mathrm{C}}$ Strongly Disagree}

(Q4) Approach 2 allowed me to gain a better understanding on why a certain account would be under- (or over-) estimated in lieu of CJE adjustment.

\section{Strongly Agree ${ }^{\mathrm{C}}$ Agree ${ }^{\mathrm{C}}$ Neutral ${ }^{\mathrm{C}}$ Disagree ${ }^{\mathrm{C}}$ Strongly Disagree}

(Q5) Approach 2 is a more effective tool in studying the topic of intra-entity transfer of inventory than Approach 1.

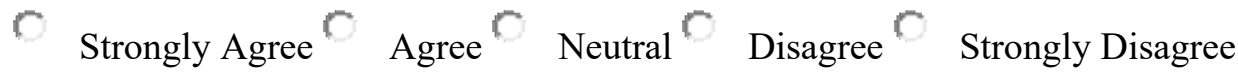

(Q6) I recommend using Approach 2 in teaching this topic in the future.

Strongly Agree ${ }^{\mathrm{C}}$ Agree ${ }^{\mathrm{C}}$ Neutral ${ }^{\mathrm{C}}$ Disagree ${ }^{\mathrm{C}}$ Strongly Disagree

(Q7) Please provide your comments in the following box/column (optional).

\section{APPENDIX C: COMMENTS IN THE END-OF CLASS-SURVEY}

- I think doing in class examples and walking us through what to do step by step helps the best.

- Approach two seemed unnecessarily complicated even if it better demonstrated exactly what was happening.

- We should spend more time on this topic and learn this in multiple ways.

- The handouts are a tremendous help!

- The approach 2 is better in delivering the material. However, in order to fully understand the topic, some practice at the end is necessary.

- The T-charts make it easier to understand the journal entries and where they come from.

- Approach one is a lot easier and easier to understand.

- I followed the lesson up until you stopped using numbers. I personally learn the best when I can see exactly how and where the numbers came from. I definitely think worksheets should be used through out all of this class for each topic. 
- I still prefer to teach both approaches so that students can gain a fuller view about intra-entity transfer of inventory. Cause after we understand how we can get the result by approach 2, we can use approach 1 to have answer more quickly.

- I think Approach 2 is easier to understand than the first. It is more straightforward and I will definitely use this one in the future.

- I think the worksheet you provided definitely provided a better understanding than approach one. I also think the worksheet will be useful for a guide on future homework problems. I understood the concept of over/under much better with approach two.

- I think this is a very difficult topic no matter how it is taught. I do like that we can visually see the $t$ accounts and are getting handouts instead of just notes, but since it is so confusing I can't really say if it is more efficient than traditional teaching.

- I like it when the topic is introduced and then I know the theory of it. Then apply the theory. That is my personal opinion.

- I think the more hands on approach that two offered allowed the material to make more sense.

- While I believe Approach 2 gives a clearer understanding but I believe Approach 1 should be overviewed as well to better clarify Approach 2.

- I thought both methods were helpful.

- Approach 2 seemed a little confusing at first, so maybe if you take that approach be more clear and go slower or repeat if more than once so students can follow better since the material is relatively hard

- I think approach 2 gives some good background info to build more of a foundation when consolidating the entries, as opposed to memorizing the entries.

- Just to help myself with this understanding, if approach \#2 was the way we discussed this information in class today $(10 / 17 / 16)$ then I strongly agree this helps to better understand the material.

- Going through the problems in the back of the book and explaining the reason behind the answer is very helpful. However it is also very good to look at multiple approaches

- Approach 2 would have worked better (for me) if the T-accounts were more clearly presented. It was a little confusing on its own, but I could understand it as you went over it.

- Starting from the beginning and covering all of the entries of the purchase and then the adjustments helped me to understand why each account is being used.

- I understood some of what happened today in class. However, there were certain parts of the lecture I didn't fully understand the accounts and the relations. When we started going over the homework problems I understood the consolidation.

- I like this style, but i have to practice this more to see if would stick. Thank you.

- Approach 2 seems to be fairly clear to follow and understand as we worked through it.

- I personally feel like approach 2 helps me to come to the same conclusions on my own and actually learn the information.

- Learning it from the beginning steps of seeing the purchase entries and then the adjusting entries clarified why the different accounts were being used. 